\title{
The Use of Staples in Dermatologic Surgery
}

\author{
IANIS P. CAMPBELL, M.D., AND NEIL A. SWANSON, M.D.
}

Staples are an excellent form of wound closure for certain types of cutaneous surgery, namely, scalp reductions, application of split-thickness grafts, axillary vault resections, and truncal excisions. Various staplers currently in use, their advantages and disadvantages, are reviewed in the context of these aforementioned procedures.

\section{INTRODUCTION}

"Records of wound closure by the use of surgical sutures and adhesive tapes have been found in ancient Egyptian writings dating to 3,000 years B.C."' Despite the number of years that have since passed we still continue to seek ideal methods of closure and care of wounds.

The possibility of using mechanical means to replace surgical sutures was a subject of considerable interest among surgeons during the past century. The first useful stapling instrument, developed by a designer of surgical instruments, Victor Fischer, in association with Hümer Hüttel, a leading surgeon at the St. Rokus Hospital in Budapest in 1911, was extremely cumbersome, weighed five kilograms, and took two hours to assemble after sterilization. In 1920, Aladár von Petz, a young surgical assistant at the University of Budapest, became interested in the problem of mechanical suturing and designed a stapler weighing only one kilogram that became a prototype for further modifications. $^{2}$

Subsequently, research in mechanical suturing devices stagnated except in Russia where The Institute for Experimental Surgical Apparatus and Instruments was established in Moscow (1951) to devise and develop stapling instruments. American designers, using

Dr. Campbell is Chief Resident in Dermatology, Department of Dermatology, University of Michigan Medical School, Ann Arbor, Michigan.

Dr. Swanson is an Assistant Professor of Dermatology and Director, Mohs Surgery Unit, Department of Dermatology, University of Michigan Medical School, Ann Arbor, Michigan.

Address reprint requests to Dr. Janis P. Campbell, M.D., Department of Dermatology, University of Michigan Medical School, Ann Arbor, MI 48109. a Russian prototype, went on to develop the preloaded, presterilized, disposable staple cartridges that are presently in use. ${ }^{3}$

\section{TYPES OF STAPLERS}

There are several disposable staplers as well as resterilizable models presently available for use in skin closures, namely, the Premium ${ }^{\mathrm{TM}}$, PSS ${ }^{\mathrm{TM}}$ and Auto Suture SFS ${ }^{T M}$ (United States Surgical Corporation, Norwalk, CT), Precise ${ }^{T M}$ (3M Center, St. Paul, MN), and Proximate I and $\mathrm{II}^{\mathrm{TM}}$ (Ethicon, Inc., Somerville, NJ). Each stapler varies in its handling characteristics, ease of positioning, staple-release mechanism, angle at which the staple is delivered, and visibility of the staple insertion site.

Each stapler is designed to produce an incomplete rectangular staple with three components-a top cross member lying parallel to the skin surface and perpendicular to the wound, two legs (height of the staple) extending into the skin, and the pointed tips that are bent inward and lie beneath the skin parallel to the cross member. The final staple configuration is achieved by squeezing the stapler handle, which causes a plunger to advance a staple around an anvil thereby forming the completed staple. ${ }^{4}$ The depth of penetration of the staple into the wound is determined and directly proportional to the amount of downward pressure applied by the staple gun against the tissue.

All of the currently marketed staples are made of inert stainless steel. No contact sensitivity has been reported, unlike that found with nickel skin clips. Neither has the chronic urticaria attributed to tantalum skin clips been reported with the stainless steel staples. ${ }^{5}$

\section{STaPlers Made by USSC}

The United States Surgical Corporation (USSC) offers a variety of skin staplers (Fig. 1). The Premium stapler consists of a prepackaged, sterile, disposable staple gun preloaded with staples that are available in two sizes. Regular-sized staples measure $4.8 \mathrm{~mm}$ wide by $3.4 \mathrm{~mm}$ high, and wide staples measure $6.5 \mathrm{~mm}$ wide by $4.7 \mathrm{~mm}$ high. Staple guns can be ordered containing 12,25 , and 35 preloaded staples. 


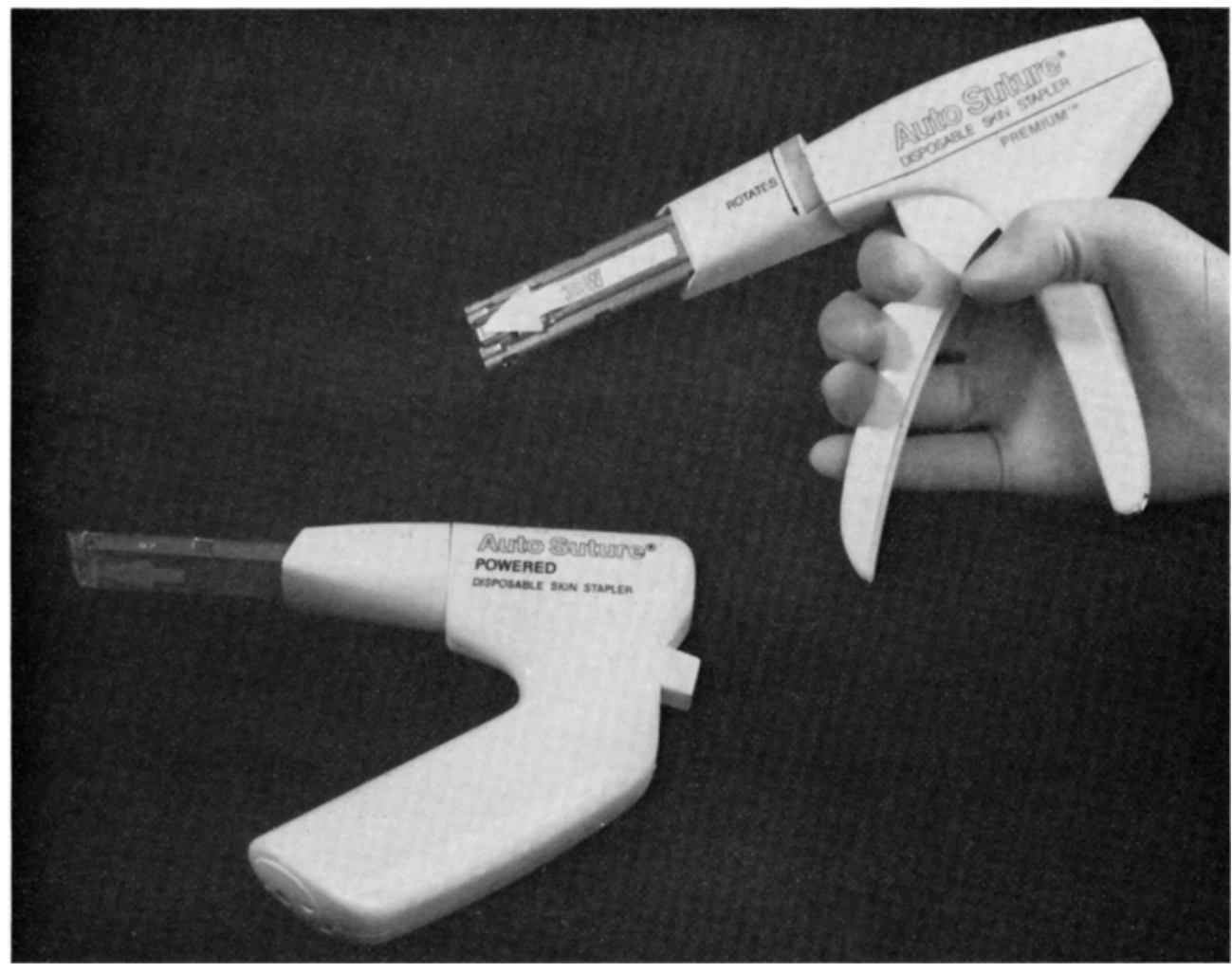

FIGURE 1. Staplers manufactured by the United States Surgical Corporation. On the lower left is the inert gaspowered model and on the upper right, the Premium ${ }^{\mathrm{TM}}$ model. The Auto Suture SFS $^{\mathrm{TM}}$ (not shown) is similar in appearance to the Premium model but made of stainless steel.
The PSS model, an inert gas-powered disposable stapler, has recently been put on the market. This unit, retailing for approximately forty dollars, appears to have no advantage over the Premium model for use in dermatologic surgery.

The Auto Suture SFS, a non-disposable model, is designed for repeated use and can be resterilized by autoclaving. Separate presterilized packets of staples can be inserted into the stapler and are available in the same quantities and sizes that accompany the Premium model. The SFS instrument requires an initial investment of five hundred and fifty dollars or can be rented at thirty dollars per month. Staple packets must be purchased separately at a cost of fifteen dollars per dozen.

The three staplers marketed by USSC share the same basic operating features. The Premium stapler, which will be used as the model for discussion, allows the operator best access to viewing the staple insertion site compared to other brands on the market. This stapler dispenses a staple at a $60^{\circ}$ angle to the tissue. Once inserted, the staple tends to assume an upright position, perpendicular to the skin surface. As it swings upright, ${ }^{*}$ a space is created between the cross

* The moving inserted staple is referred to as a "floating staple" by the manufacturers. member of the staple and the tissue. This is important because if direct contact of the cross member and the tissue occurs, cross-hatching of the incision line has a greater likelihood of occurring, especially if significant swelling of tissues occurs postoperatively.

A precock mechanism, present in both the Premium and SFS models, but not in the gas-powered model, partially forms the staple and exposes the staple tips. With this feature, initiated by partial pressure on the handles, the exposed ends of the partially formed staples can be used to achieve more accurate placement of staples and, in addition, can be used as skin hooks to facilitate approximation of skin edges. ${ }^{4}$ Additional pressure on the grip handle completes the shaping of the staple and causes an ejector spring to automatically propel the staple away from the anvil foot into the tissue.

Another significant feature of the Premium and other USSC models consists of a swivel tip that allows for a $360^{\circ}$ rotation of the nose piece. Used in combination with the long nose piece in all USSC models, the swivel tip makes USSC staplers the best for gaining easy access to recessed locations. Furthermore the Premium model has the advantage over the Auto Suture SFS unit of being disposable and not requiring a large initial investment, a factor important to the dermatologist who does only occasional surgical closures. 
Staplers Made by Ethicon, Inc.

The Proximate I stapler consists of two Lexan plastic handles that are hinged anteriorly (Fig. 2). This unit weighs three ounces and is available with 15,35 , or 55 staples in a cartridge. Staples are available in two widths, namely, regular size, $5.7 \mathrm{~mm}$ wide by $3.9 \mathrm{~mm}$ high, and wide size, $6.9 \mathrm{~mm}$ wide by $3.9 \mathrm{~mm}$ high. The Proximate II is a more compact model of the Proximate I and is small enough to fit in the palm of one's hand.

The Ethicon units function much like a desk stapler. To insert a staple, wound edges are first everted and aligned into a recess on the anterior-inferior surface of the nose piece. A centering arrow on the nose piece facilitates alignment of the tissue into this recess. Then continuous pressure is applied to the stapler handles as they are squeezed together. Because there is no precock mechanism on the Proximate, if discontinuous pressure is applied, the staple may fail to obtain the correct configuration and slip off the anvil. Following compression of the handles the staple enters the tissue equidistant from the edges of the incision at a $90^{\circ}$ angle. Because of the angle of insertion, no "floating" of the staple occurs. Therefore, if excessive pressure is applied to the stapler during staple insertion, the cross member may be left flush with the skin edges, resulting in permanent cross-hatching.
In contrast to the USSC models, the Proximate I and II staplers do not possess an ejector spring release. Consequently following insertion of the staple into the tissue, the staple remains around the anvil. The stapler must be moved posteriorly from the staple insertion site to disengage the staple.

Because of the angle of insertion and the shape of the stapler, visual access to the site of staple insertion is more limited than with the Premium stapler. The Proximate II, however, offers better visibility of the site than the Proximate I due to a shorter nose. Also with the Proximate models, the staple count can be monitored only by referring to the bottom of the magazine, while the Premium stapler allows easy visual access to the number of staples being used.

Although the suppliers do not recommend re-use, Stegmaier ${ }^{6}$ recently reported resterilization was possible by autoclaving but that this process may result in occasional jamming of the mechanism.

\section{Staplers Made by THE 3M CoRporation}

The newest stapler on the market is the Precise stapler by $3 \mathrm{M}$ (Fig. 3). This stapler comes prepackaged with 15 or 30 staples in regular size, $5.0 \mathrm{~mm}$ wide by $3.5 \mathrm{~mm}$ high, and wide size, $7.5 \mathrm{~mm}$ wide by $4.2 \mathrm{~mm}$ high. These "wide" staples are considerably wider than the others on the market.

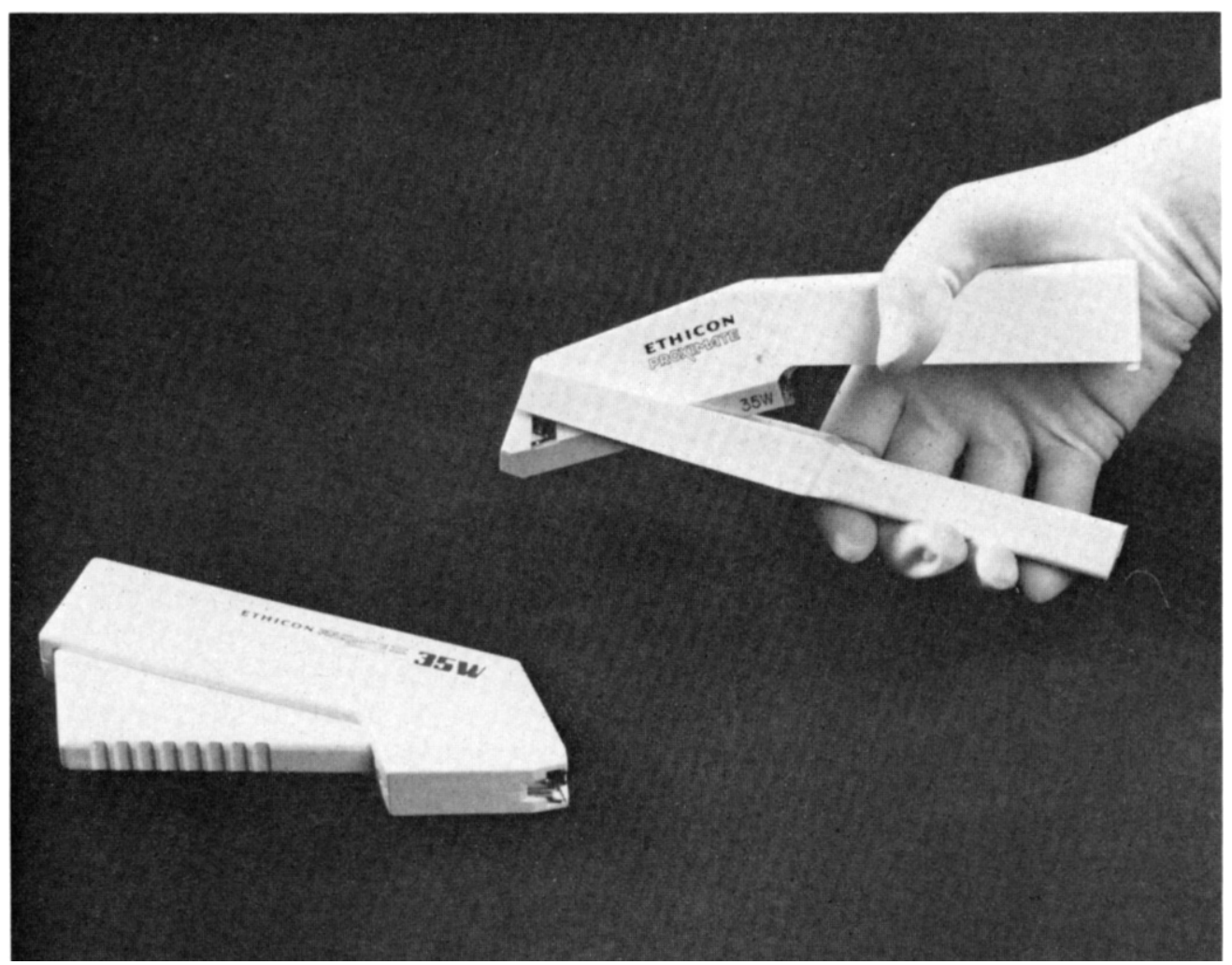

FIGURE 2. Staplers made by Ethicon. On the lower left is the Proximate $I^{\mathrm{TM}}$ model and on the upper right, the Proximate $I^{\mathrm{TM}}$ unit. 


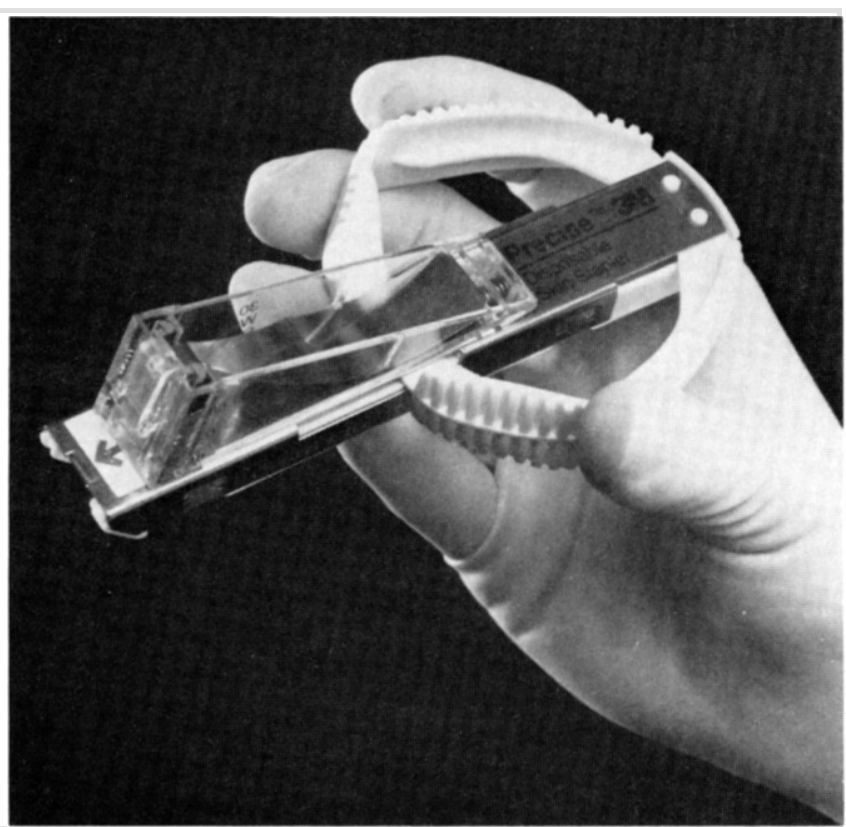

FIGURE 3. The Precise ${ }^{\mathrm{TM}}$ stapler made by the $3 M$ Corporation.

The Precise stapler, unlike the others on the market, is held like a pair of forceps at a forty-five degree angle to the skin edges. The stapler can be held in a variety of positions, one of which is illustrated in Fig. 3. Compression of the handles inward results in staple formation and ejection. A precock mechanism in the Precise stapler is obtained with partial compression of the handles. Care must be taken, as with the Proximate stapler, to evert the edges of the wound up into the recess of the nose of the stapler. Again a centering arrow facilitates alignment of the staples with the wound edges. As with the Premium model, there is a lesser chance of cross-hatching of the wound due to the angle of staple insertion. This angle is approximately sixty degrees. The Precise model does not possess an ejector spring release. As a result the stapler must be moved anteriorly from the staple insertion site to disengage the staple. This model also offers excellent visibility of the staple insertion site and the remaining staple count.

\section{USE OF STAPLES IN DERMATOLOGIC SURGERY}

In preparation for closure, a wound should be prepared in the usual fashion by undermining and freshening of the skin edges. Buried sutures can be placed to remove tension and align skin edges if needed. To evert and approximate wound edges, tissue forceps as well as manual pressure can be used. Staples may then be inserted. With the Precise and Premium models, which have precock mechanisms, incompletely formed staples can be placed as temporary stay sutures to mechanically ease the alignment of the edges, and in the case of long wounds, to divide these into smaller closures. Use of regular or wide staples is based on the condition of the skin. Regular-size staples should be used for thin, poor quality, or normal skin while the wider staples are recommended for closures of good quality, normal- to thick-skin closures.

\section{Advantages of Wound Closure by Staples}

Rapid closure of wounds is the main advantage of staples, as wound closure using staples can be done approximately fifty percent faster than with sutures. Since staples can be used easily on the trunk, scalp, face, and extremities, they can be extremely useful in the application of split-thickness skin grafts to a recipient site (Figs. 4-9). Staples significantly decrease the time required for graft application, by alleviating the tedious suture work of joining the periphery of a graft

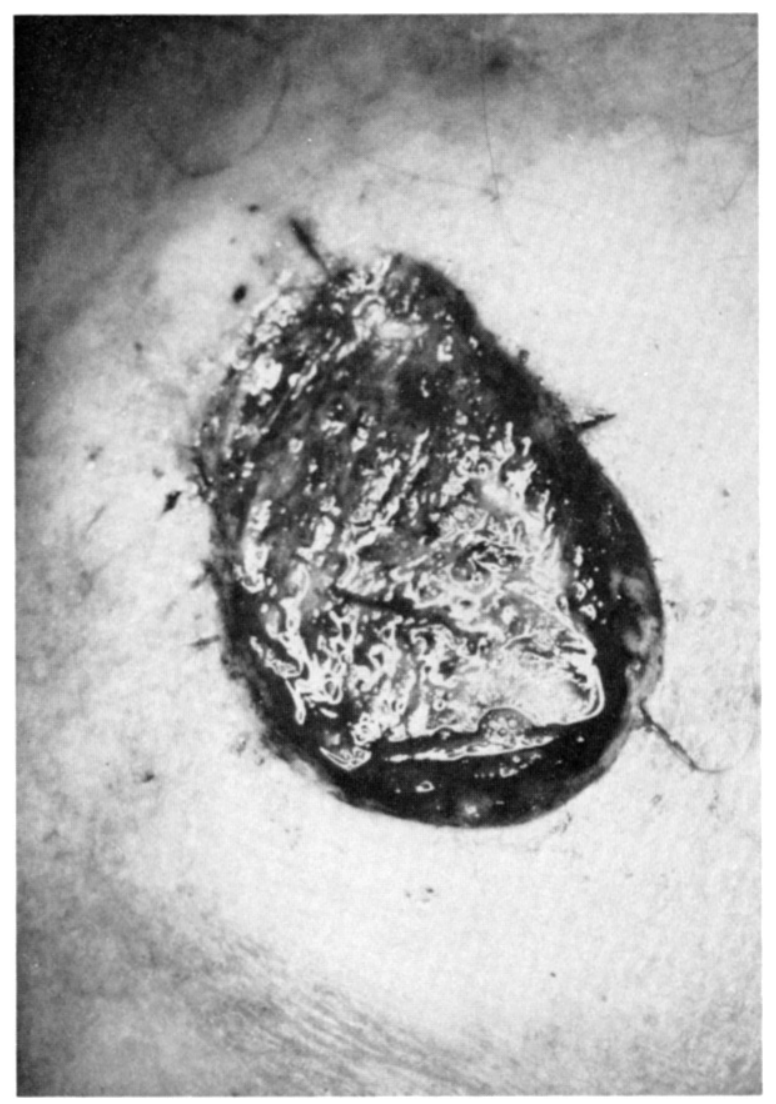

FIGURE 4. Appearance of a skin defect on the forehead to be repaired by a split-thickness skin graft. 


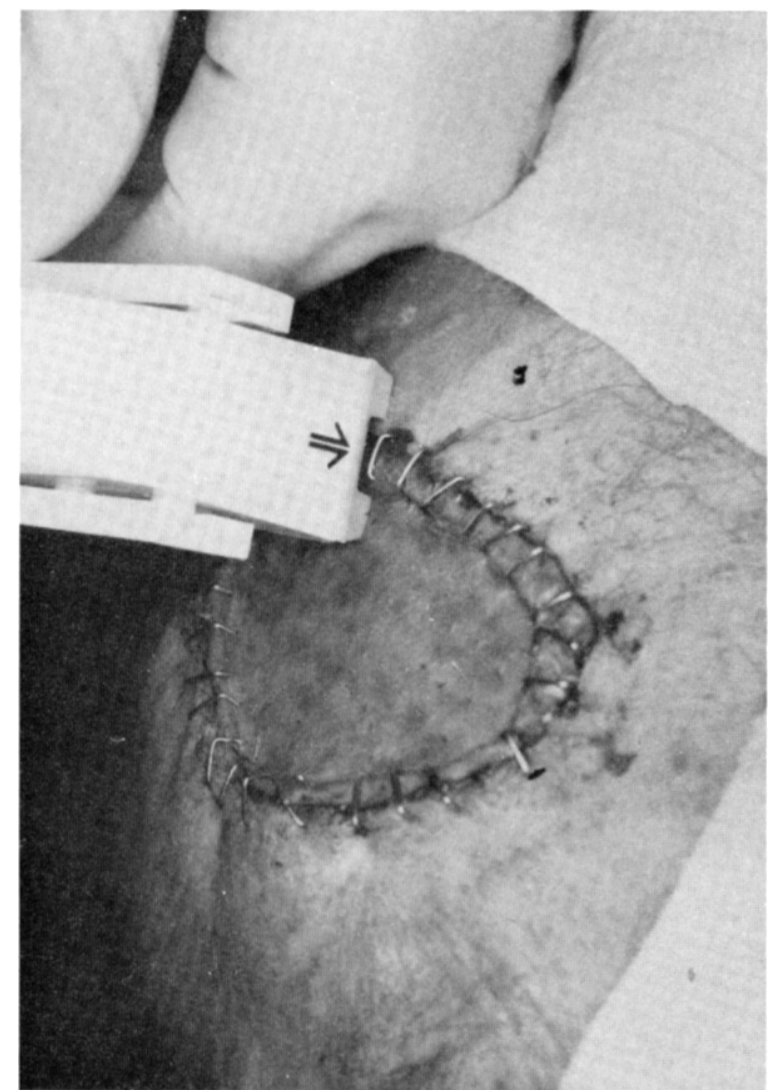

FIGURE 5. Insertion of staples circumferentially around the graft.

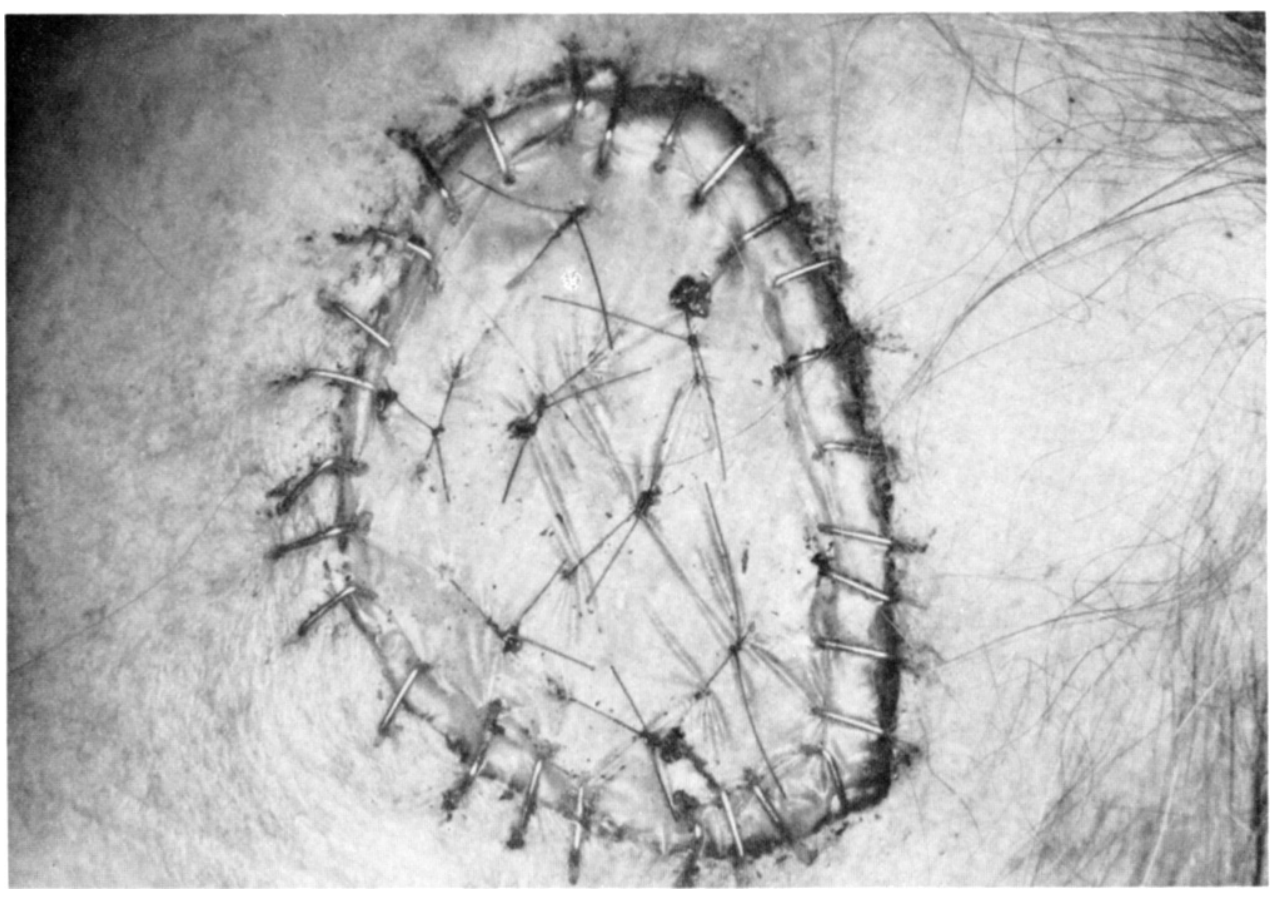

FIGURE 6. Completion of application of graft using staples peripherally and basting sutures centrally. 
FIGURE 7. Removal of staples one week later.
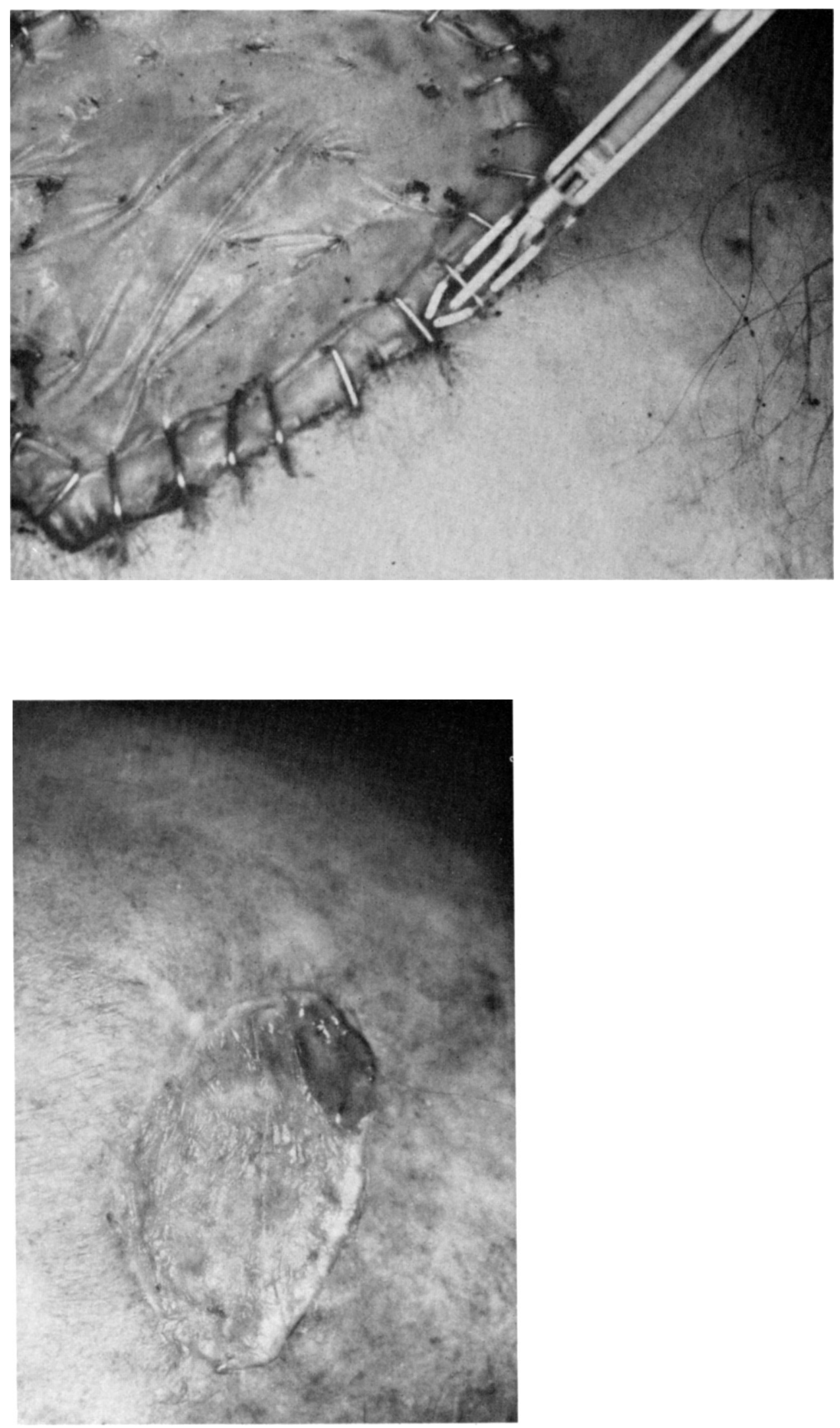

FIGURE 8. Appearance of the graft three weeks postoperatively. 


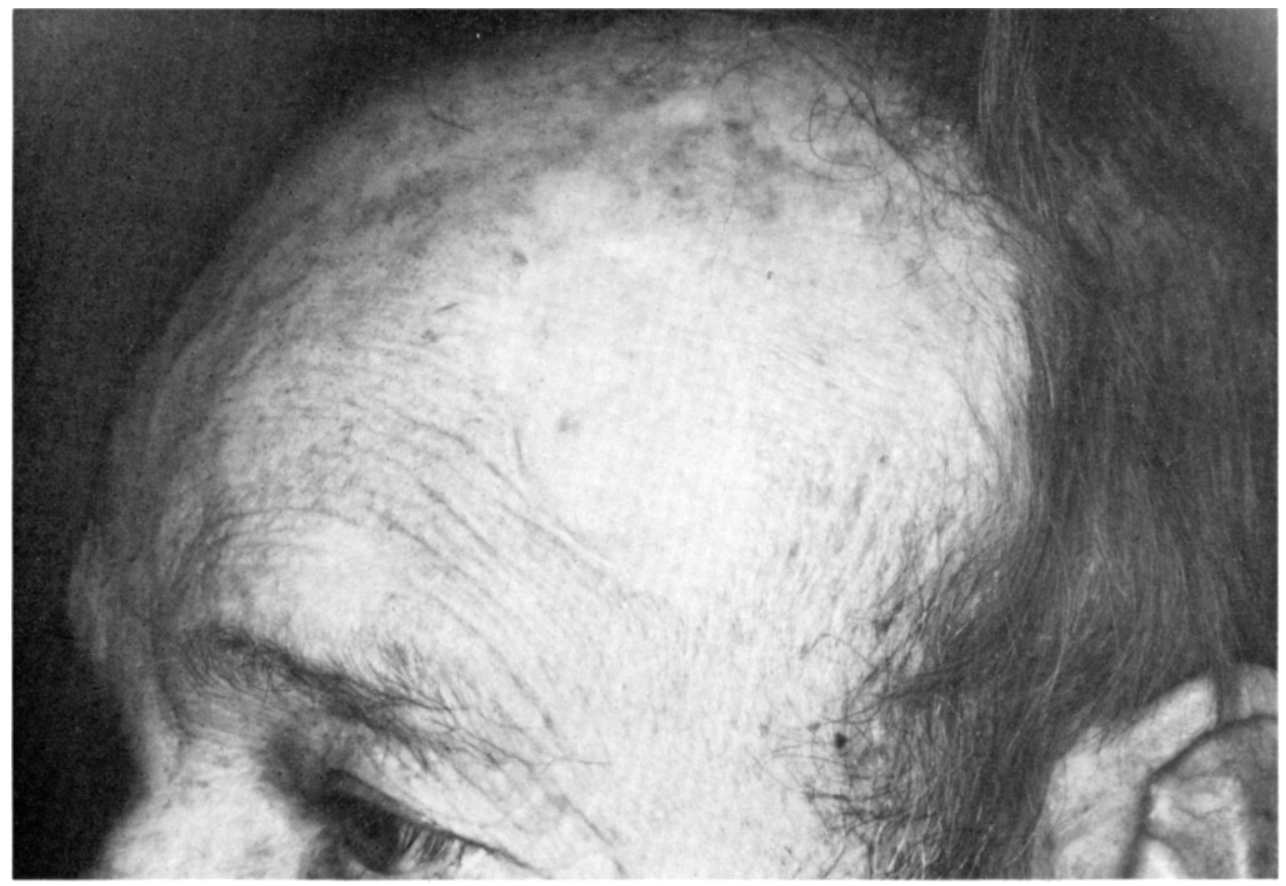

FIGURE 9. Appearance of the graft ten months postoperatively. to a receipient bed. ${ }^{7}$ After a dermatome split-thickness graft is obtained, trimmed and arranged on the recipient bed, three or four staples are initially placed equidistant to each other to approximate the graft to the recipient bed. Subsequently, staples are inserted to fully secure the edges circumferentially. The staples must be angled to appose the graft to the concave edge of the bed. Basting staples may then be used to tack down the center of the graft if necessary.

Staples may also be used in the closure of scalp reductions. Stapling significantly reduces operating time without altering cosmesis. Once the scalp wedge has been removed a subcutaneous layer of sutures can be placed in the galea and the skin closed with staples (Figs. 10 and 11).

Susceptibility of surgical wounds to surface contamination by Staphylococcus aureus in experimental animals has shown that in undressed wounds, closure using staples was more resistant to infection compared with those closed by nylon or silk sutures. Only closure with subcuticular polyglycolic acid sutures with buried knots, protected by a painted-on dressing as found by Stillman et al., ${ }^{8}$ and closure with skin tapes ${ }^{4}$ were more resistant to infection than staples. Decreased conduction of surface bacteria by the staples, as well as the atraumatic application of staples during skin closure, may explain these observations. This property of staples makes them even more desirable for use in axillary vault resections for hidradenitis suppurativa, where bacterial overgrowth and abscess formation are common (Figs. 12 and 13). By substituting staples for sutures, one can easily reduce operating time from one hour down to thirty minutes, and similarly reduce the chances of postoperative infection. Although the use of staples in intertriginous areas can occasionally cause patients some discomfort, Stegman, Tromovitch, and Glogau ${ }^{9}$ reported how they used staples in the entire axilla following excisions for hidradenitis suppurativa without complaints from their patients.

Because stainless steel staples are chemically inert and cause little tissue reaction, they can be left in tissues for a longer period of time than non-absorbable sutures in an attempt to prevent spreading of the suture line. In closures on the trunk, where spreading commonly occurs, one can purposely keep surgical staples in the skin for three weeks (Figs. 14-16). Another approach to prevent spreading of wounds is to over-evert the wound edges, which is easily accomplished using staples. Traub and Quattlebaum ${ }^{10}$ removed cutaneous staples after three days and replaced them with skin tapes for an additional five days. They found that this procedure decreased the incidence of persistently visible puncture sites, and decreased the spreading of wounds when compared to results of staples left in for eight days. Although skin tapes can help in limiting the spreading of wounds, it may be prudent to limit their use in the very early postoperative period as their adhesiveness may vary with wound conditions. Reepithelization of a wound is apparently 
FIGURE 10. Outline of planned excision for scalp reduction.

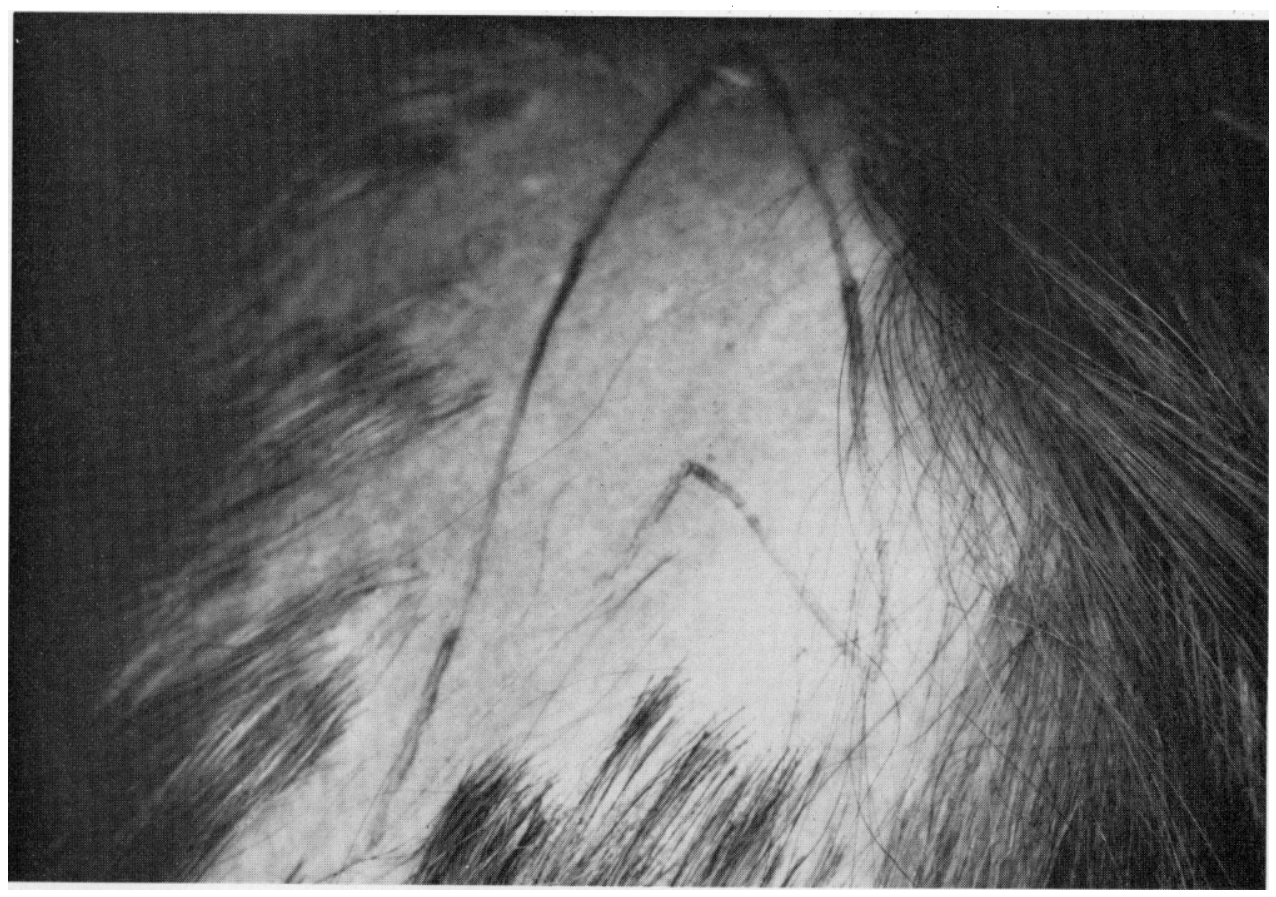

FIGURE 11. Closure of scalp reduction with staples.

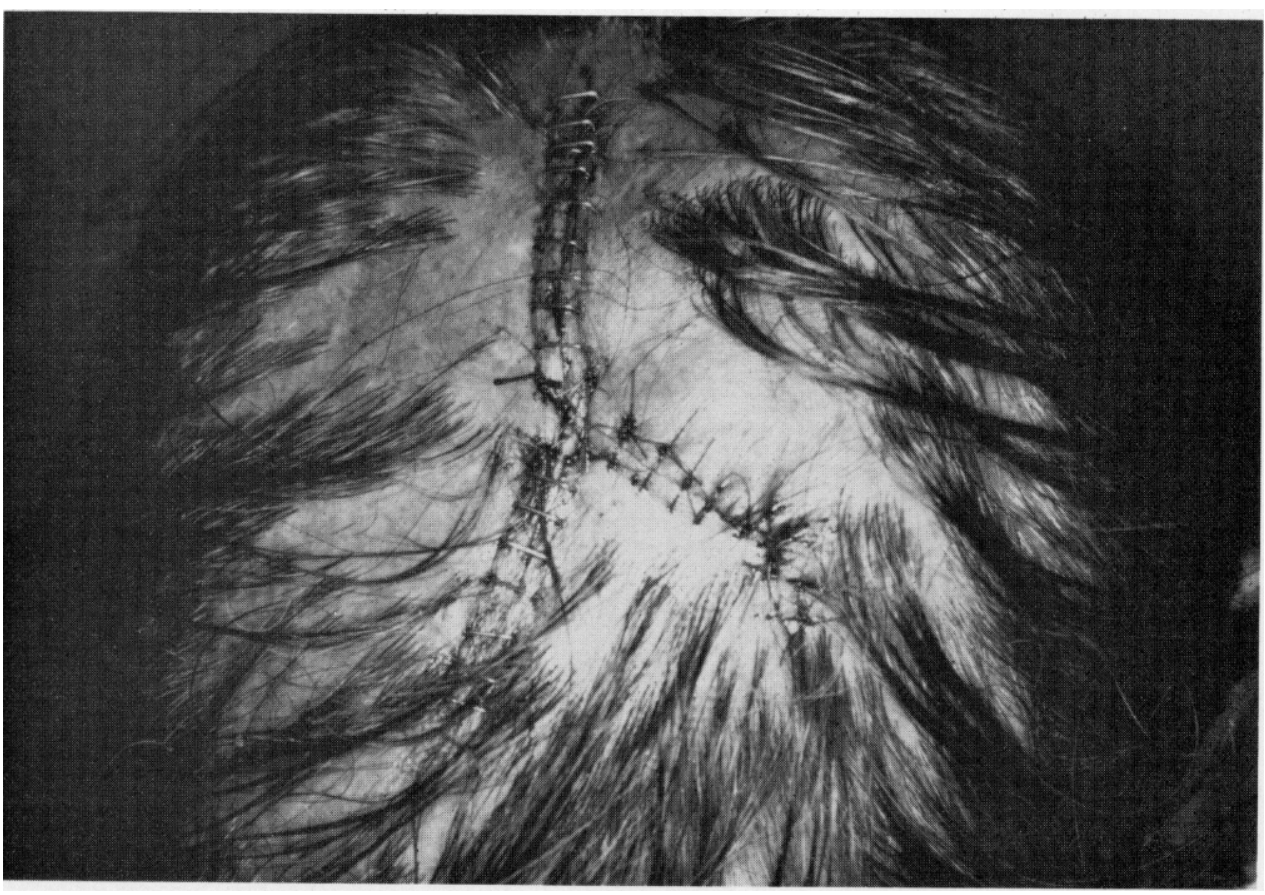




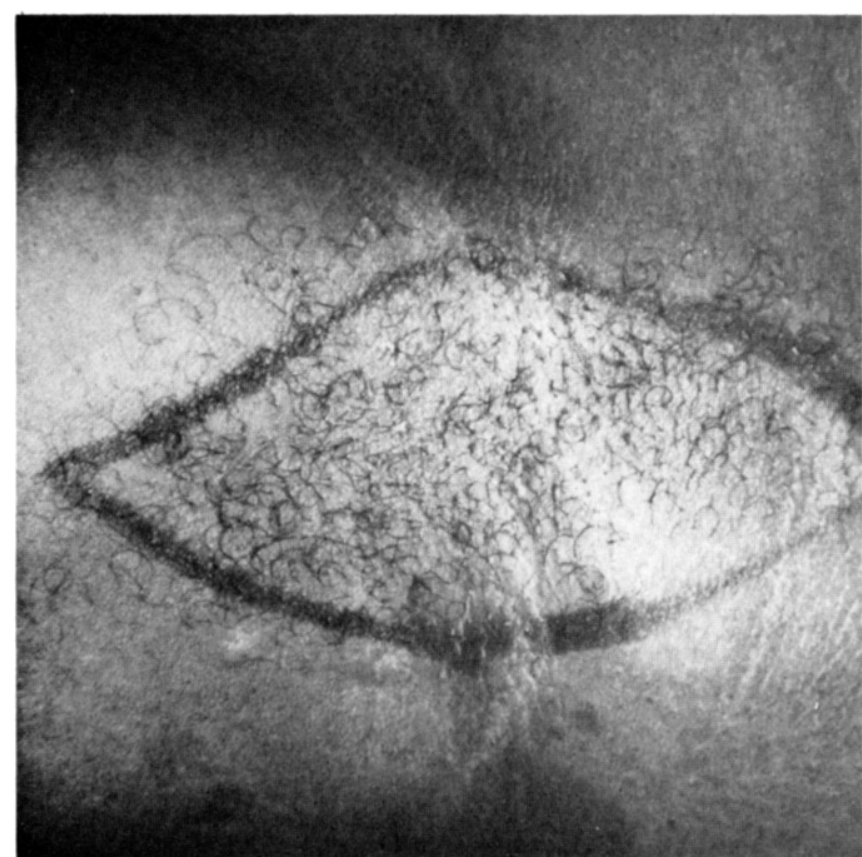

FIGURE 12. Outline of planned excision for hyperhidrosis of axilla.

complete within $48-72$ hours $^{11}$ but the tensile strength is negligible. Therefore if a shear stress is applied to a taped wound, especially if the tapes have impaired adhesion due to moisture from secretions or perspiration, dehiscence is possible. In general for routine clo-

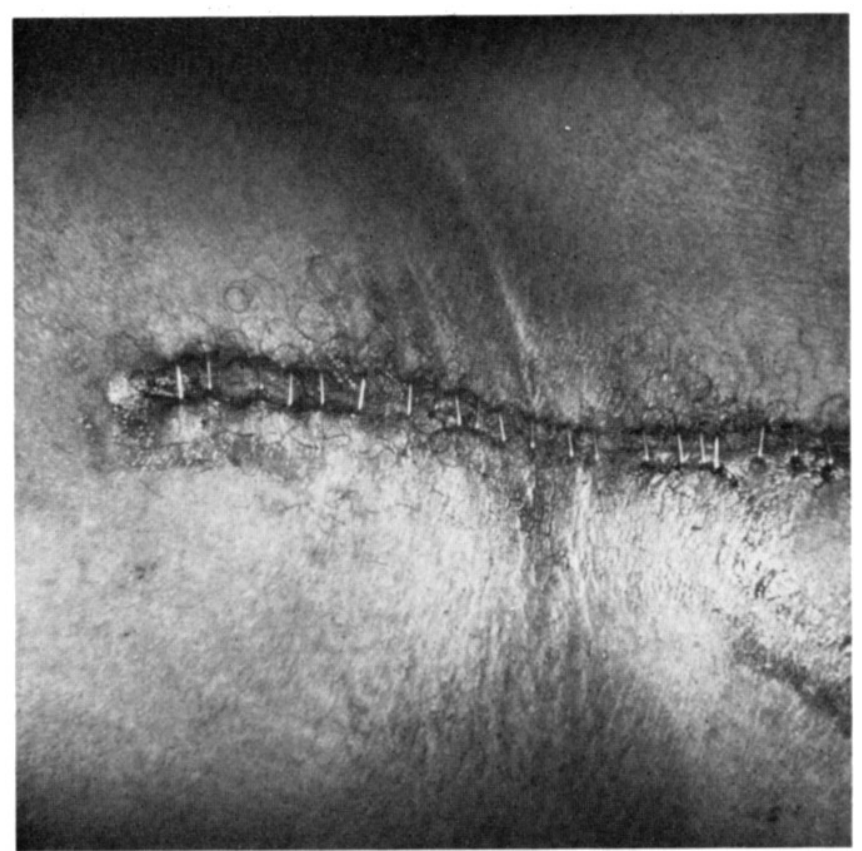

FIGURE 13. Closure of axillary excision with staples.

sures, staples are removed at the same intervals as sutures.

Finally removal of staples is painless and staples are much easier to remove than sutures, especially in hair-bearing areas such as the scalp (staples are highly

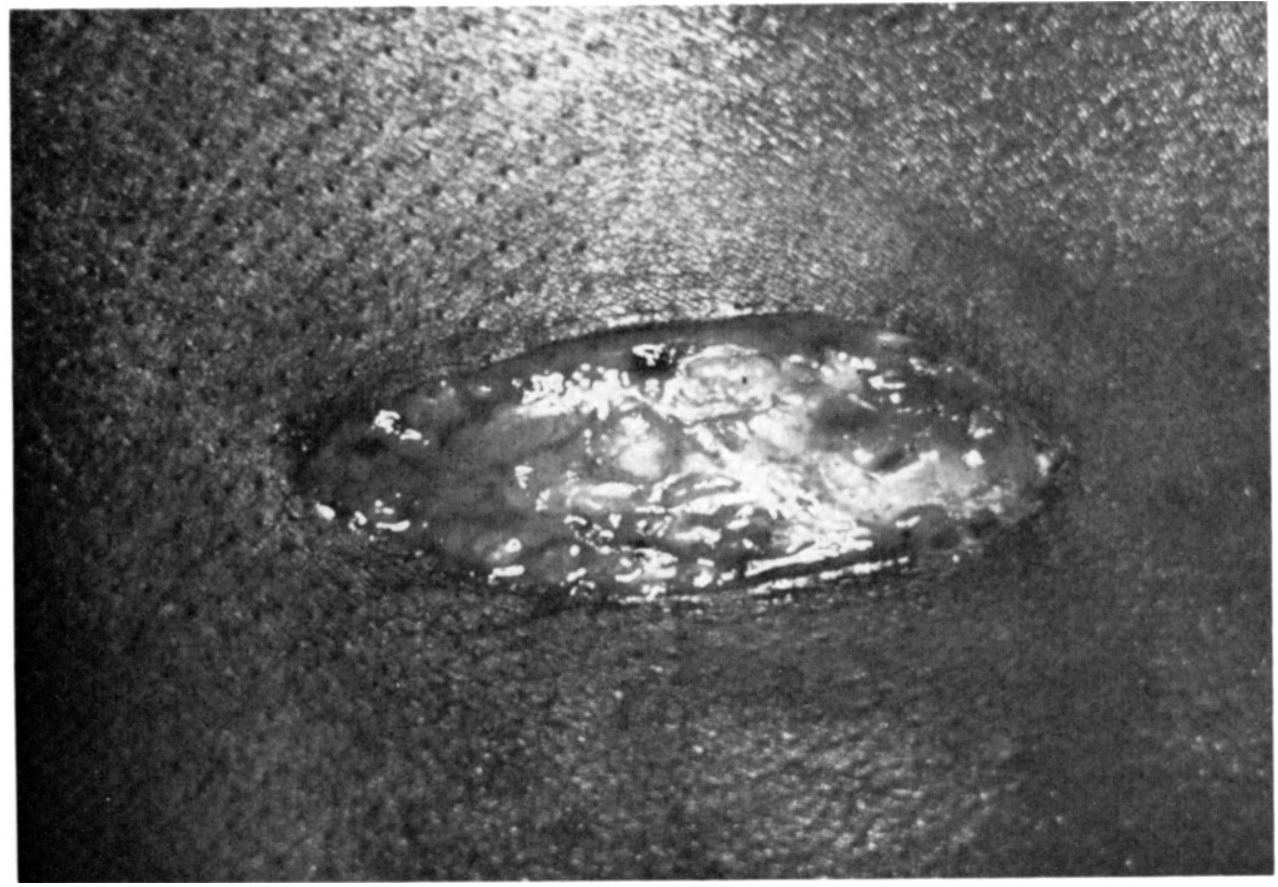

FIGURE 14. Appearance of a defect following excision of a basal-cell carcinoma on the lateral trunk. 
FIGURE 15. Closure of truncal excision with staples.

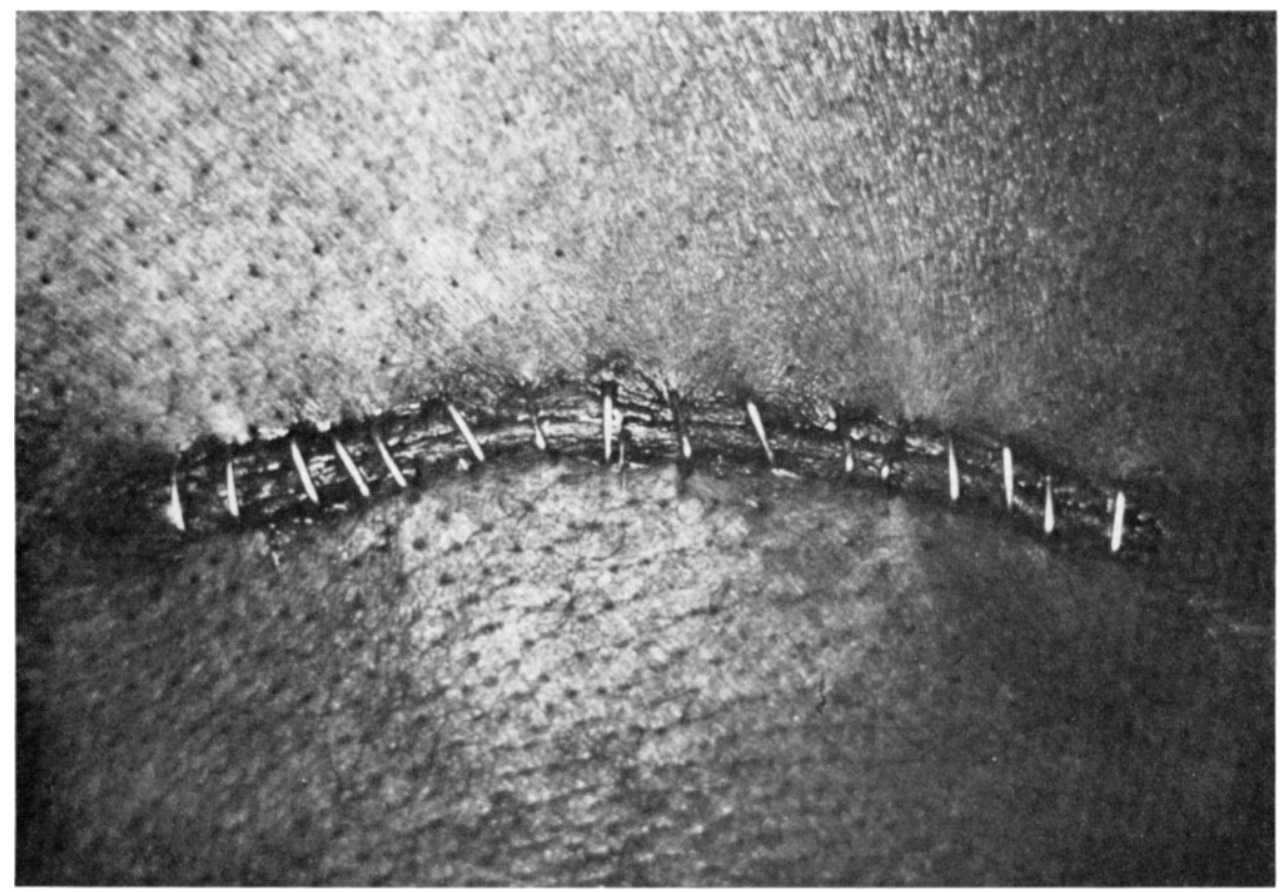

visible compared with dark-colored sutures) and in crusted suture sites. To remove a staple, the tips of the double lower jaws of a staple remover are slid under the staple (Fig. 17) and the handles are then squeezed together which causes the other jaw to compress the staple in the center, and the bent tips are then lifted out, away from the skin.

Disadvantages of Wound Closure by Staples

The primary disadvantage of staples compared to sutures as a means of closing wounds is their lack of
FIGURE 16. Appearance of the wound three months postoperatively. Staples were left in the wound for three weeks in an attempt to prevent spreading of the suture line.

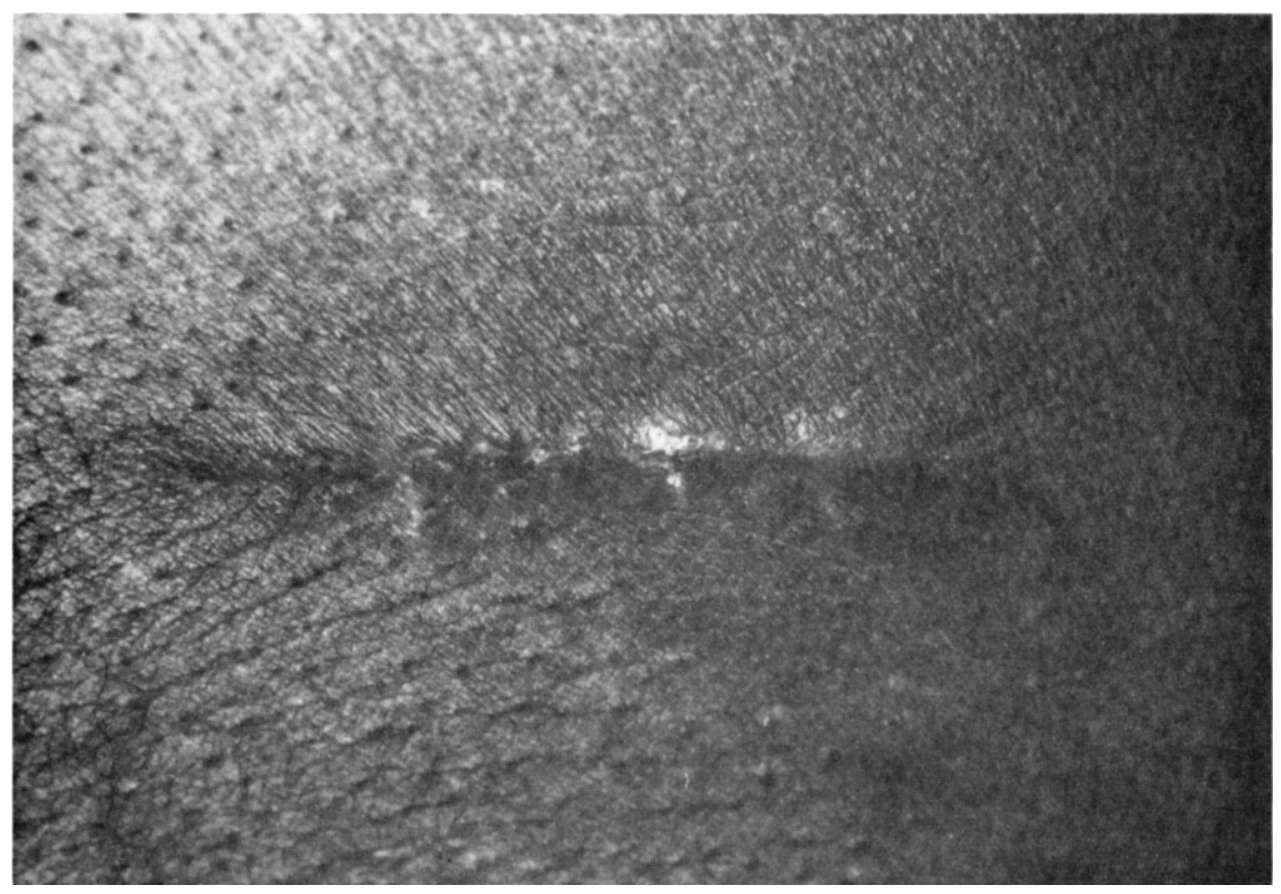




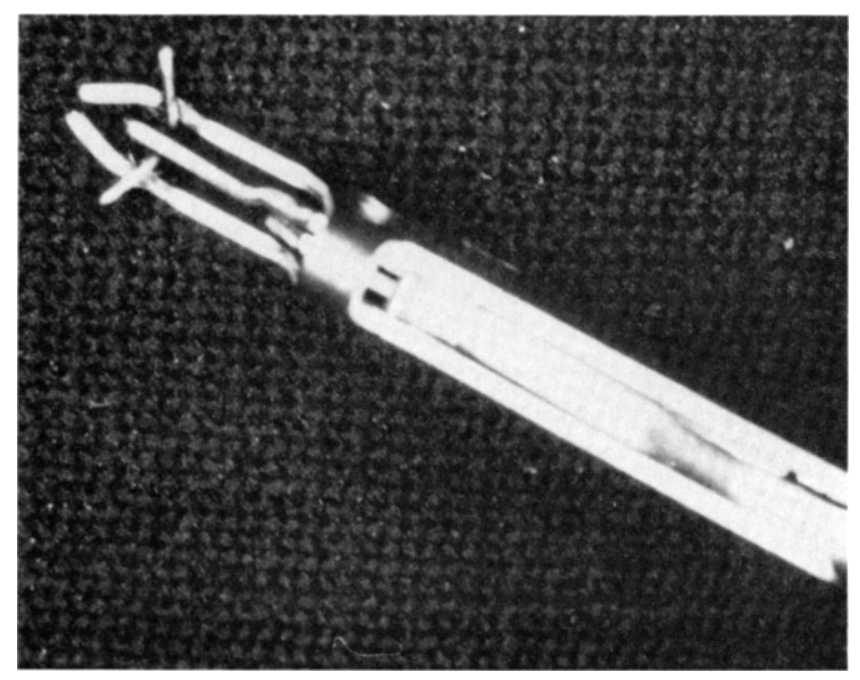

FIGURE 17. A staple remover. The upper jaw' of the remover compresses the cross member of the staple against the two lower jaws.

fine cosmetic closures on areas such as the face. Here the use of running subcuticular sutures offers superior results.

The cost of staplers has been mentioned as a disadvantage by many surgeons. Though the eighteen dollar price of most disposable staple guns is more than the cost of suture material, one must weigh the savings in time when evaluating the price. For example, the use of staples is not cost or time efficient in the closure of a punch biopsy site since only one to two staples would be needed. Use of the remaining staples would entail resterilization which may result in jamming of the mechanism upon reuse.

In summary we have reviewed the features of staplers and their current use in dermatologic surgery. At present they are not an ideal method of closure for all surgical procedures, but there are definite indications for their use. Staples offer an excellent form of wound closure for certain types of cutaneous surgery, such as scalp reductions, split-thickness graft applications, axillary vault resections, and truncal excisions. As stated by Steichen and Ravitch" "machines cannot replace or improve man's thinking; if used properly, they can, however, add precision, neatness, and speed the execution and completion of his decisions."

\section{ACKNOWLEDGEMENT}

Special thanks to Charles N. Ellis, M.D., who provided advice on the manuscript and to Darlene Callahan for typing the manuscript.

\section{REFERENCES}

1. Stephens, F. O., and Niesche, J. W. The use of an automatic stapling device for closure of surgical wounds. Aust. N.Z. J. Surg. 44:398-402, 1974.

2. Robicsek, F. The birth of the surgical stapler. Surg. Gynecol. Obstet. 150:579-583, 1980.

3. Cooper, P., and Tolins, S. H. Stapling as a method of suturing tissues. Ann. Surg. 2:51-59, 1970.

4. Johnson, A., Rodeheaver, G. T., Durand, L. S., Edgerton, M. T., and Edlich, R. F. Automatic disposable stapling devices for wound closures. Ann. Emerg. Med. 10:631635, 1981.

5. Werman, B. S., and Rietschel, R. L. Chronic urticaria from tantalum staples. Arch. Dermatol. 117:438-439, 1981.

6. Stegmaier, O. C. Use of skin stapler in dermatologic surgery. J. Am. Acad. Dermatol. 6:305-309, 1982.

7. Swanson, N. A., Tromovitch, T. A., Stegman, S. J., and Glogau, R. G. Skin grafting: The split-thickness graft in 1980. J. Dermatol. Surg. Oncol. 6:524-526, 1980.

8. Stillman, R. M., Bella, F. J., and Seligman, S. I. Skin wound closure: The effect of various wound closure methods on susceptibility to infection. Arch. Surg. 115:674-675, 1980 .

9. Stegman, S. J., Tromovitch, T. A., and Glogau, R. G. Basics of Dermatologic Surgery. Chicago, Year Book Medical Publishers, Inc., 1982, pp 13-15.

10. Traub, A. C., and Quattelbaum, F. W. Cutaneous wound closure: Early staple removal and replacement by skin tapes. Contemp. Surg. 18:93-101, 1981.

11. Harris, D. R. Healing of the surgical wound. J. Am. Acad. Dermatol. 1:208-215, 1979.

12. Steichen, F. M., and Ravitch, M. M. Mechanical sutures in surgery. Br. J. Surg. 60:191-197, 1973. 